\section{Cerastium arcticum, Lange}

Is contending that Murbeck and Ostenfeld made the combination Cerastium edmondstonii "in contradiction to the rules of botanical nomenclature", and that "therefore the name $C$. edmondstonii is illegitimate" (presumably on the ground of redundancy, as a mere change of status of the type indicated is of itself perfectly legitimate), Miss O. E. Brett ${ }^{1}$ is labouring inter alia under the common assumption that the European plant is conspecific with those described by Johan Lange principally from Greenland as $C$. arcticum. Having some years ago worked in west Greenland (from parts of which most of Lange's material came) and found there specimens seemingly indistinguishable from those in Herb. Copenhagen determined by him as $C$. arcticum, I ventured to question the validity of this assumption ${ }^{2}$; my feeling that, whatever the status of the European plant, Lange's Greenland material is best treated within the polymorphic complex $C$. alpinum s.l. was supported by the late A. J. Wilmott, and, apparently, by Clapham, Tutin and Warburg ${ }^{3}$, who uphold $C$. edmondstonii and give among its synonyms " $C$. arcticum auct., vix Lange". Earlier on, Ostenfeld before his death and also Gelting ${ }^{4}$ appear to have come to the conclusion that all the Greenland plants should be referred to $C$. alpinum. The cytological information so far available is not very helpful.

Whether or not Murbeck and Ostenfeld "only redescribed Lange's plant" when they "took the varietal epithet, var. edmondstonii, and gave it specific rank" is beside the point, as their new combination was validly published and devolves upon the type described originally from Shetland. If this last is indeed specifically distinct from Lange's 'plant' (which appears to be something of a mixture ${ }^{5}$, so that a type specimen would have to be selected if the entity were to be upheld) it should be called $C$. edmondstonii ${ }^{6}$ - unless there is serious doubt as to its identity, in which event a new name might have to be given to it (or an old one such as $C$. nigrescens resurrected, though this itself has had a peculiar history ${ }^{5}$ ). However, further cytogenetic and other investigation (which I cannot myself at present andertake) may indicate that the problem is more complex even than it sounds, with the solution still, as in too many taxonomic instances, dependent upon personal opinion.

Nicholas Polunin

Harvard University, Cambridge 38, Mass.

${ }^{1}$ Nature, 171, 527 (1953).

2 J. Linn, Soc., Bot., 52, 382 (1943).

3 "Flora of the British Isles", 299 (Cambridge University Press, 1952).

- Medd. om Gronland, 101, No. 2, 36 (1934)

- Fernald and Wiegand in Rhodora, 22, 175 (1920).

- International Code of Botanical Nomenclature, Utrecht (1952).

To present all the relevant information in order to discuss this point of nomenclature would require more space than is available in these columns. I shall therefore confine myself to stating that Murbeck and Ostenfeld ${ }^{1}$ chose deliberately to name this species $C$. edmondstonii rather than $C$. arcticum (which latter name they then regarded as a synonym) because the species was originally described as $C$. latifolium var. edmondstonii. This procedure is, of course, contrary to Article 70 of the International Code of Botanical Nomenclature.

I realize that there are certain difficulties in upholding the name $C$. arcticum, Lange. Ultimately, it is a matter of personal opinion whether Lange's description (which in the absence of a type specimen becomes the type) is acceptable. It seems to me that Lenge distinguishes between his plant and $C$. alpinum quite clearly ; moreover, his description of C. arcticum fitted the material which I was using in my cytological investigation.

The situation among these species is, indeed, highly involved. It is possible that further cytogenetic research, upon which I am at present engaged, will reveal that the Shetland plant is a distinct species, and it is also probable that a form of $C$. alpinum $(2 n=72)$ is one of the parents, which, by hybridization with another species, produced $C$. arcticum $(2 n=108)$.

Queen Mary College,

Olive E. Brett

Mile End Road, London, E.1.

${ }^{1}$ Bot. Notiser, 246 (1898).

\section{Descartes and Atomism}

THE Cartesian philosophical concept of the nature of matter has frequently been given indefinite interpretation or assessment in the literature.

The earliest coherent hypothesis postulating matter to be constituted of discrete particles is due to Democritus the Abderite. The predisposing cause of the development of the concept was the desire to make intelligible the perceived qualitative differences in the multitudinous types of known material substances. The particles of Democritus, while being constituted of the same fundamental matter, were considered to possess various shapes and sizes; in addition, they were determined absolutely by being indivisible. Aggregations of various numbers and types of particles explained the empirical phenomenon of variety in macroscopic matter. Particles and void solely constituted material nature for the Greeks.

Greek thought differs only in detail and elaboration from the Daltonian atomic concept; indeed, the influence of the Greek philosophy on Dalton can be traced through the intermediaries Gassendi and Newton. Dalton and Democritus did not differ in fundamental purpose (except in extent of this), namely, to explain the constitution and empirical properties of matter in terms of the properties and arrangements of hypothetical discrete particles. The existence of such a purpose and the associated particle concept necessary to resolve it provide. the criterion which defines the true atomist.

The nature and utilization of the particle hypothesis of Descartes was entirely different. Although he built the universe of particles, these were endowed with divisibility', and he substituted the void of the ancient atomists by his "matière fort subtile"s. The particles of Descartes were therefore in no sense atomic, but only pieces of matter lacking the necessary atomic property of ultimateness. Further, he used his ideas not in any Græco-Daltonian sense but as basis for a mechanical philosophy. It is quite incorrect, therefore, to attribute any development of atomism to Descartes ; rather was he a 'deviationist' who, on the basis of a debssed 'atomic' theory, produced a theory of mechanical cosmology ${ }^{3}$.

Technical College, Blackburn.

J. GRUNDY Sept. 28.

1 "Les Météores" (Discours premier).

2 "Principia Philosophiø", Part iv, sect. 102.

s"Principia Philosophiæ", Part ili, sect. 52, 55-50, 63-64. 